\title{
СЛОЖНОСТИ МОЛЕКУЛЯРНОЙ ДИАГНОСТИКИ СИНДРОМА РЕЗИСТЕНТНОСТИ К АНДРОГЕНАМ ПРИ ГЛУБОКОЙ ИНТРОННОЙ МУТАЦИИ В ГЕНЕ AR
}

\author{
Н.Ю. Калинченко', В.М. Петров', А.В. Панова', А.Н. Тюльпаков ${ }^{2}$ \\ 'ФГБУ «Национальный медицинский исследовательский центр эндокринологии» Минздрава \\ России, Москва, \\ 2Медико-генетический научный центр имени академика Н.П. Бочкова», Москва
}

Мутации в гене X-сцепленного рецептора андрогенов (AR) лежат в основе синдрома нечувствительности к андрогенам (AIS), наиболее распространенной причины нарушения формирования пола 46,XY. Однако, около 10\% пациентов с AIS, несмотря на наличие клинико-лабораторных признаков заболевания, не имеют мутаций в кодирующей области $\mathrm{AR}$, что оставляет неопределенность в окончательной верификации диагноза.

ЦЕЛЬ: уточнение молекулярной основы заболевания у пациента с AIS и отсутствием мутаций в кодирующей последовательности гена AR.

МЕТОДЫ: Секвенирование ДНК проводилось методом Сенгера.

PЕЗУЛЬТАТЫ: Пациент М, при рождении мошоночная форма гипоспадии, кариотип 46,XY; зарегистрирован в мужском паспортном поле. В детском возрасте проведена маскулинизирующая пластика. В 12 лет в связи с развитием гинекомастии обследован эндокринологом: при осмотре феминное телосложение, половое развитие G2P2B3, яички в мошонке $12 \mathrm{~cm}^{3}$. в гормональном профиле: ЛГ - 5,0 Ед/л (2,5-11,0), ФСГ - 0,9Ед/л (1,55-9,74), тестостерон - 17,8 нмоль/л $(0,9-12,5)$, Э2 - 120 пмоль/л (20-60). Установлен диагноз «синдром резистентности к андрогенам, неполная форма». Однако, при секвенировании геномной ДНК (экзоны 1-8 и соответствующие экзон-интронные стыки) мутаций в гене AR выявлено не было. При секвенировании кДНК, полученной их фибробластов кожи мошонки, помимо транскрипта AR дикого типа (NM_000044.3) выявлен аберрантный транскрипт, содержащий вставку из 40 нуклеотидных оснований (с.2450_2451 insc.25140_c.251-1). Дополнительное секвенирование последовательности интрона 6 гена AR выявило гемизиготную транзицию hg19_chrX:67722785G>A, приводящую к образованию альтернативного акцепторного сайта сплайсинга.

Выводы: данное наблюдение иллюстрирует сложности молекулярно-генетической диагностики AIS и подчеркивает важность использования дополнительных методов (секвенирование кДНК) при отсутствии изменений в кодирующих областях гена AR.

КЛЮЧЕВЫЕ СЛОВА: рецептор к андрогенам; резистентность к андрогенам; нарушение формирования пола; аберрантный транскрипт; альтернативный акцепторный сайт сплайсинга. 